\title{
A thermostable hybrid cluster protein from Pyrococcus furiosus: effects of the loss of a three helix bundle subdomain
}

\author{
Marieke L. Overeijnder · Wilfred R. Hagen • \\ Peter-Leon Hagedoorn
}

Received: 20 January 2009/ Accepted: 5 February 2009/Published online: 25 February 2009

(C) The Author(s) 2009. This article is published with open access at Springerlink.com

\begin{abstract}
Pyrococcus furiosus hybrid cluster protein (HCP) was expressed in Escherichia coli, purified, and characterized. This is the first archaeal and thermostable HCP to be isolated. Compared with the protein sequences of previously characterized HCPs from mesophiles, the protein sequence of $P$. furiosus $\mathrm{HCP}$ exhibits a deletion of approximately $13 \mathrm{kDa}$ as a single amino acid stretch just after the N-terminal cysteine motif, characteristic for classIII HCPs from (hyper)thermophilic archaea and bacteria. The protein was expressed as a thermostable, soluble homodimeric protein. Hydroxylamine reductase activity of $P$. furiosus $\mathrm{HCP}$ showed a $K_{\mathrm{m}}$ value of $0.40 \mathrm{mM}$ and a $k_{\text {cat }}$ value of $3.8 \mathrm{~s}^{-1}$ at $70{ }^{\circ} \mathrm{C}$ and $\mathrm{pH}$ 9.0. Electron paramagnetic resonance spectroscopy showed evidence for the presence of a spin-admixed, $S=3 / 2[4 \mathrm{Fe}-4 \mathrm{~S}]^{+}$cubane cluster and of the hybrid cluster. The cubane cluster of $P$. furiosus $\mathrm{HCP}$ is presumably coordinated by a $\mathrm{CXXC}-\mathrm{X}_{7}-\mathrm{C}-\mathrm{X}_{5}-\mathrm{C}$ motif close to the N-terminus, which is similar to the $\mathrm{CXXC}-\mathrm{X}_{8}-$ $\mathrm{C}-\mathrm{X}_{5}-\mathrm{C}$ motif of the Desulfovibrio desulfuricans and Desulfovibrio vulgaris HCPs. Amino acid sequence alignment and homology modeling of $P$. furiosus HCP reveal that the deletion results in a loss of one of the two three-helix bundles of domain 1. Clearly the loss of one of the three-helix bundles
\end{abstract}

M. L. Overeijnder · W. R. Hagen · P.-L. Hagedoorn ( $\square)$

Department of Biotechnology,

Delft University of Technology,

Julianalaan 67, 2628 BC Delft,

The Netherlands

e-mail: p.l.hagedoorn@tudelft.nl

Present Address:

M. L. Overeijnder

DSM Research,

Koestraat 3, 6160 MD Geleen,

The Netherlands of domain 1 does not diminish the hydroxylamine reduction activity and the incorporation of the iron-sulfur clusters.

Keywords Electron paramagnetic resonance · Hybrid cluster protein - Hydroxylamine reductase . Iron-sulfur cluster · Pyrococcus furiosus

\section{Introduction}

The hybrid cluster protein (HCP), also known as prismane protein or fuscoredoxin in earlier literature, contains two different iron-sulfur clusters $[1,2]$. The first cluster, coordinated by four cysteines near the N-terminus of the protein, is either a regular cubane-type [4Fe-4S] cluster or a $[2 \mathrm{Fe}-2 \mathrm{~S}]$ cluster. The second cluster is the unique hybrid [4Fe-2O-2S] cluster and has been named so because of the fact that it is a hybrid between an iron-sulfur and an ironoxo cluster. The cubane cluster presumably functions in electron transfer. The hybrid cluster lies buried at the center of the protein and the distance to the cubane cluster is 11-12 $\AA$. The hybrid cluster has an asymmetric open structure that undergoes a gross structural rearrangement upon reduction, suggesting it is the site of catalytic activity $[2,3]$.

HCPs are widely distributed among (facultative) anaerobic microorganisms, including bacteria, archaea, and unicellular eukaryotes. HCPs from Desulfovibrio vulgaris, Desulfovibrio desulfuricans, and Escherichia coli have been isolated and characterized. Differences in the predicted primary structures allow differentiation of three classes of HCPs [4-6]. Class-I HCPs have a distinct $\mathrm{N}$-terminal iron-sulfur cluster binding motif: $\mathrm{C}-\mathrm{X}_{2}-\mathrm{C}-$ $\mathrm{X}_{7-8}-\mathrm{C}-\mathrm{X}_{5}-\mathrm{C}$. Class-I $h c p$ genes have so far been found in strict anaerobic bacteria and primitive eukaryotes (e.g., 
D. vulgaris, D. desulfuricans, Clostridium acetobutylicum, Giardia, Trichomonas vaginalis, Entamoeba). Class-II HCPs have a longer spacing between the second and the third cysteine of the $\mathrm{N}$-terminal iron-sulfur cluster binding motif: $\mathrm{C}-\mathrm{X}_{2}-\mathrm{C}-\mathrm{X}_{11}-\mathrm{C}-\mathrm{X}_{6}-\mathrm{C}$. Class-II $h c p$ genes have been found in Gram-negative bacteria (e.g., E. coli, Morganella morganii, Thiobacillus ferrooxidans). In the classII HCP from E. coli the N-terminal iron-sulfur cluster binding motif coordinates a $[2 \mathrm{Fe}-2 \mathrm{~S}]$ cluster. Class-II $h c p$ genes are found in a dicistronic operon with an $h \mathrm{cr}$ gene encoding an iron-sulfur flavoprotein which is an NADHdependent HCP reductase [5]. Class-III proteins have the same N-terminal iron-sulfur cluster binding motif as the class-I proteins, but they have a deletion of aproximately 100 amino acid residues downstream of this motif. ClassIII proteins are found in (hyper) thermophilic bacteria and archaea (e.g., Pyrococcus furiosus, Ignococcus hospitalis, Moorella thermoacetica, Methanobacterium thermoautotrophicum, Thermatoga maritima).

HCP shares some sequence and structural homology with the $\mathrm{CO}$ dehydrogenase protein family ( $\mathrm{CO}$ dehydrogenase and the bifunctional $\mathrm{CO}$ dehydrogenase/acetyl-CoA synthase) [7], which is concentrated in a striking structural similarity between the protein environment of the hybrid $\left[\mathrm{Fe}_{4} \mathrm{O}_{2} \mathrm{~S}_{2}\right]$ cluster of $\mathrm{HCP}$ and that of the $\left[\mathrm{NiFe}_{4} \mathrm{~S}_{4-5}\right]$ cluster of $\mathrm{CO}$ dehydrogenase. Previously it was found that a change in catalytic properties takes place upon substitution of key residues that bind to the $\mathrm{CO}$ dehydrogenase $\left[\mathrm{NiFe}_{4} \mathrm{~S}_{4-5}\right]$ cluster. This substitution converts $\mathrm{CO}$ dehydrogenase from an enzyme that catalyzes $\mathrm{CO}$ oxidation to one that has a hydroxylamine reductase activity [7]. It was also found that insertion of iron in the vacant position of nickel-deficient $\mathrm{CO}$ dehydrogenase leads to a similar hydroxylamine reductase activity. The similarity of the hybrid cluster with the ironsubstituted NiFeS active-site cluster of Rhodospirillum rubrum $\mathrm{CO}$ dehydrogenase suggested that HCP may be able to reduce hydroxylamine as well. Indeed it was found that E. coli $\mathrm{HCP}$ can reduce hydroxylamine to ammonia; however, $K_{\mathrm{m}}$ for hydroxylamine is in the millimolar range [8]. Therefore it is not likely that hydroxylamine is the physiological substrate of HCP. Concentrations of hydroxylamine in the millimolar range are toxic to $E$. coli cells, despite the presence of HCP in this organism [9].

The $h c p$ gene has been found to be under the control of transcription factors that are related to anaerobicity and protection against reactive nitrogen species: Fnr, OxyR, NarL, and NsrR [10-12]. The transcription of $h c p$ appears to be coregulated with the NADH-dependent periplasmic nitrite reductase Nir in E. coli [10]. It has been shown for E. coli and M. morganii that HCP expression is induced when they are grown anaerobically in the presence of nitrate or nitrite [4]. Conflicting results have been reported on the phenotype of the $h c p$ knockout with respect to the sensitivity towards hydrogen peroxide: it makes $C$. perfringens less sensitive and E. coli more sensitive. The $h c p$ knockout of Rhodobacter capsulatus has lost the ability to grow on hydroxylamine as the only nitrogen source [9]. All these regulatory data suggest that HCP is somehow involved in the metabolism (or detoxification) of reactive nitrogen species under anaerobic conditions.

Recently HCP was found to catalyze the reduction of hydrogen peroxide with ascorbate [11]. For D. vulgaris and D. desulfuricans HCP, the reactivity is of the same order of magnitude as hydroxylamine reduction activity; however, the catalytic efficiency of this reaction is very low.

In contrast to the extensive characterization of class-I and to a lesser extent of class-II HCPs, there are only gene sequence data for the class-III HCPs. Therefore, it is not known what effect the large deletion of approximately $13 \mathrm{kDa}$ may have on the iron-sulfur clusters and on the catalytic properties of the protein. DNA microarray analysis proved that the class-III $h c p$ gene from $P$. furiosus is transcribed in vivo. An upregulation of $h c p$ transcription was measured when $P$. furiosus cells were grown on peptides compared with starch [13]. The expression level of $h c p$ in P. furiosus is insufficient for purification from the wild-type organism. In this report we describe the recombinant expression, purification, and characterization of the class-III HCP from the hyperthermophile P. furiosus.

\section{Materials and methods}

\section{Cultivation}

Pyrococcus furiosus strain DSM 3638 was cultivated anaerobically at $90{ }^{\circ} \mathrm{C}$ on a complex medium with starch as the carbon source [14] or on a complex peptide medium supplemented with elemental sulfur [15]. After cultivation, the cell pellet was used for genomic DNA extraction. Genomic DNA was isolated using phenol-chloroform extraction.

\section{Cloning}

The $h c p$ gene was amplified using the following primers: PFhcp1Forward 5'-CACCATGGAAATGGCCATACG-3' (NcoI site underlined) and PFhcp1Reverse 5'-GTCCGTC GACTCAATCAAGTTCTTC-3' (SalI site underlined). The $\overline{\mathrm{PCR}}$ reaction was performed with Pfx polymerase (Invitrogen) or Taq polymerase (GE Healthcare). The primer combination PFhcp1Forward/PFhcp1Reverse results in a product of 1,392 bp. PCR products were used for TOPO TA cloning (Invitrogen) according to the manufacturer's instructions. Isolated plasmids were digested with their corresponding restriction enzymes (Roche) and cloned into 
the pET24d expression vector. These plasmids were transformed into E. coli BL21-CodonPlus (DE3)-RIL (Stratagene) and sequenced for confirmation.

\section{Reverse transcriptase PCR}

Total P. furiosus RNA was isolated from cells grown overnight at $95{ }^{\circ} \mathrm{C}$ on complex peptide medium supplemented with elemental sulfur [15], using the RNeasy mini kit (Qiagen), according to the manufacturers' instructions. The reverse transcription and PCR were carried out sequentially with the OneStep reverse transcriptase PCR (RT-PCR) kit (Qiagen) using a T1 Thermocycler (Biometra) and using PFhcp1Forward and PFhcp1Reverse primers for the production of complementary DNA. Reverse transcription was performed for $30 \mathrm{~min}$ at $50{ }^{\circ} \mathrm{C}$. PCR was performed according to the following protocol: $5 \mathrm{~min}$ at $94{ }^{\circ} \mathrm{C}, 30$ cycles of $1 \mathrm{~min}$ at $94{ }^{\circ} \mathrm{C}, 1 \mathrm{~min}$ at $53{ }^{\circ} \mathrm{C}, 1 \mathrm{~min}$ at $72{ }^{\circ} \mathrm{C}$ followed by $10 \mathrm{~min}$ at $72{ }^{\circ} \mathrm{C}$. A control PCR was performed using the same PCR protocol.

\section{Overexpression and isolation of $P$. furiosus $\mathrm{HCP}$}

Escherichia coli strains were grown on terrific broth medium supplemented with kanamycin $(25 \mu \mathrm{g} / \mathrm{mL})$ and chloramphenicol $(50 \mu \mathrm{g} / \mathrm{mL})$ under a nitrogen atmosphere at $37^{\circ} \mathrm{C}$. Iron(III)citrate $(0.01 \mathrm{~g} / \mathrm{L})$ was added prior to induction to facilitate the biosynthesis of iron-sulfur clusters. At the mid-exponential growth phase (optical density $0.4-0.6$ ), the culture was induced with $1 \mathrm{mM}$ isopropyl $\beta$-D-thiogalactopyranoside and cooled to $28^{\circ} \mathrm{C}$. After $18 \mathrm{~h}$ of induction, the cells were harvested, yielding typically $3.5 \mathrm{~g} / \mathrm{L}$ cells (wet weight). The cells were washed in $50 \mathrm{mM}$ tris(hydroxymethyl)aminomethane hydrochloride (Tris- $\mathrm{HCl}$ ), pH 8.0 containing $1 \mathrm{mM}$ EDTA, $1 \mathrm{mM}$ phenylmethylsulfonyl fluoride, and approximately 5,000 U DNase. The cells were lysed using a cell disrupter (constant system). The cell extract was centrifuged for $1 \mathrm{~h}$ at $14,000 \mathrm{~g}$. The supernatant was concentrated using a Centriprep centrifugal filtration device with a $30-\mathrm{kDa}$ cutoff (Millipore). Subsequently, the concentrated cell-free extract was passed through a $0.2-\mu \mathrm{m}$ filter (Millipore).

All high performance liquid chromatography purification steps were performed using a Merck L-6210 Intelligent pump connected to a Waters 991 photodiodearray detector. All buffers used for purification were passed through a $0.2-\mu \mathrm{m}$ filter and degassed. The $\mathrm{pH}$ of all the buffers was adjusted at room temperature.

The cell-free extract was loaded onto a Poros HQ anionexchange column (Applied Biosystems) at a flow rate of $2 \mathrm{~mL} / \mathrm{min}$. This column was equilibrated with $50 \mathrm{mM}$ Tris- $\mathrm{HCl}, \mathrm{pH}$ 8.0. A gradient of $0-1.0 \mathrm{M} \mathrm{NaCl}$ in the same buffer was applied. Brown HCP containing fractions eluted between 125 and $330 \mathrm{mM} \mathrm{NaCl}$ and were pooled. After concentration with a Centricon centrifugal filter with a $30-\mathrm{kDa}$ cutoff (Millipore), the sample was run through a Superdex 200 gel-filtration column (GE Healthcare) at a flow rate of $1 \mathrm{~mL} / \mathrm{min}$. This column had been previously equilibrated with $10 \mathrm{mM}$ potassium phosphate $/ 150 \mathrm{mM}$ $\mathrm{NaCl}, \mathrm{pH} 7.0$ buffer. Fractions that had the highest absorbance at $390 \mathrm{~nm}$ were pooled and concentrated with a Centricon filter (30-kDa cutoff). The yield of pure $P$. furiosus $\mathrm{HCP}$ was $8 \mathrm{mg} / \mathrm{L}$ culture.

The protein purity was estimated by sodium dodecyl sulfate (SDS) polyacrylamide gel electrophoresis (PAGE). Gel electrophoresis was carried out with a PhastSystem (GE Healthcare) according to the manufacturer's instructions. Phastgradient gels (10-15\%) and SDS buffer strips were used. A sample buffer $(10 \mathrm{mM}$ Tris- $\mathrm{HCl} \mathrm{pH} 8.0$, $2 \mathrm{mM}$ EDTA, $10 \% \beta$-mercaptoethanol, $0.025 \%$ bromophenol blue) was mixed 1:1 with the sample and boiled for 5 min.

The native molecular weight was determined by native PAGE. Native PAGE was performed using a PhastSystem (GE Healthcare) using a $8-25 \%$ gradient PAGE gel with native buffer strips and native high molecular weight markers (all from GE Healthcare) according to the manufacturer's protocol.

\section{Hydroxylamine reductase activity assay}

The assay mixture contained $100 \mathrm{mM}$ 2-(N-cyclohexylamino)ethanesulfonic acid $\mathrm{pH}$ 9.0, $10 \mu \mathrm{M}$ EDTA, $10 \mathrm{mM}$ methyl viologen and was prepared under anaerobic conditions. For each measurement $1 \mathrm{~mL}$ assay mixture was used. Small aliquots (less than $1 \mu \mathrm{L}$ ) of sodium dithionite $(100 \mathrm{mM})$ were added to reduce the methyl viologen until it had an absorbance of 1 at $600 \mathrm{~nm}$, which corresponds to a concentration of $0.103 \mathrm{mM}$ reduced methyl viologen. UV-vis absorbance was measured using a fiber-optic spectrophotometer (Avantes). Unless stated otherwise, $10 \mathrm{mM}$ hydroxylamine was added as the substrate to the anaerobic assay mixture. The reaction was started by adding HCP. The decrease of absorbance at $600 \mathrm{~nm}$ was measured over several minutes. One unit of HCP activity was defined as $1 \mu \mathrm{mol}$ hydroxylamine reduced per minute. The enzyme activity values were not corrected for the amount of apoprotein.

Ammonia, the product of hydroxylamine reduction, was measured enzymatically using glutamate dehydrogenase (Sigma-Aldrich) as follows. The assay reaction mixture contained $100 \mathrm{mM}$ Tris-HCl pH 7.3, $15 \mathrm{mM} \alpha$-ketoglutarate, $0.25 \mathrm{mM}$ EDTA, $0.1 \mathrm{mM}$ NADH. To the $1,350 \mu \mathrm{L}$ assay mix, $100 \mu \mathrm{L}$ HCP sample and $50 \mu \mathrm{L} 100 \mathrm{U} / \mathrm{mL}$ glutamate dehydrogenase were added. The decrease in 
absorption was measured over several minutes at $340 \mathrm{~nm}$ using the fiber-optic spectrophotometer.

Analytical procedures and spectroscopic methods

The iron content was determined in a colorimetric assay as the ferene complex [16]. For protein determination the bicinchoninic acid assay kit (Uptima) was used.

The N-terminal sequence of the recombinant HCP was determined after blotting onto a poly(vinylidene difluoride) membrane in a gas-phase sequenator at the Sylvius laboratories (Department of Medical Biochemistry, Leiden University, The Netherlands).

EPR data were recorded using a Bruker ER200D EPR spectrometer with a National Instruments interface and data acquisition and analysis software written in LabView/ FORTRAN95. The liquid-helium cooling was as previously described [17]. The microwave frequency was measured with an HP5350B frequency counter. The modulation frequency was always $100 \mathrm{kHz}$. The powersaturation behavior of the EPR signals with amplitude $A$ was fitted to the equation $A=1 /\left[1+\left(P / P_{1 / 2}\right)^{0.5}\right]$, in which $P_{1 / 2}$ represents the power at $50 \%$ saturation of the EPR signal. The simulations of the EPR signals in Figs. 2a and 3 were based on $g$-strained $S=1 / 2$ systems according to [18]. The simulation of the signal in Fig. $2 \mathrm{~b}$ is based on an $E / D$-strained $S=9 / 2$ system [19].

Homology modeling of P. furiosus HCP

A homology model of $P$. furiosus HCP was generated using the 3D-JIGSAW comparative modeling server using D. vulgaris HCP (Protein Data Bank entry 1gnt) as a template [20]. The 3D-JIGSAW program generated proper alignment of the N-terminal iron-sulfur cluster binding motif, unlike other protein modeling servers such as SWISS-MODEL. Figures were prepared using PyMOL (DeLano Scientific).

\section{Results}

Expression and purification of P. furiosus HCP

Class-I and class-II HCPs from different species have been isolated and characterized before $[1,5,9,21]$. Here we describe the first characterization of a class-III HCP. Owing to the low expression levels of HCP in P. furiosus, the $h c p$ gene was overexpressed in E. coli using a pET expression system.

Expression plasmids were assembled in which the $h c p$ gene was placed downstream of the T7lac promoter. The purified protein showed a single band at $52 \mathrm{kDa}$ on an
SDS-PAGE gel (not shown). This is in good agreement with the expected molecular mass of $51.3 \mathrm{kDa}$, based on the amino acid sequence. The identity of the purified protein was confirmed by sequencing of 20 amino acids at the $\mathrm{N}$-terminus. The purified HCP had a specific hydroxylamine reductase activity of $3.70 \mathrm{U} / \mathrm{mg}$ at $70{ }^{\circ} \mathrm{C}$.

Iron determination of recombinant $P$. furiosus $\mathrm{HCP}$ resulted in $2.7 \mathrm{Fe} /$ molecule. In the case of full occupation of a hybrid cluster and a $[4 \mathrm{Fe}-4 \mathrm{~S}]$ cluster $8 \mathrm{Fe} /$ molecule can be expected. The observation of a brown color of the protein indicates the presence of iron-sulfur clusters. EPR spectroscopy was used to probe the nature of the ironsulfur clusters in P. furiosus HCP.
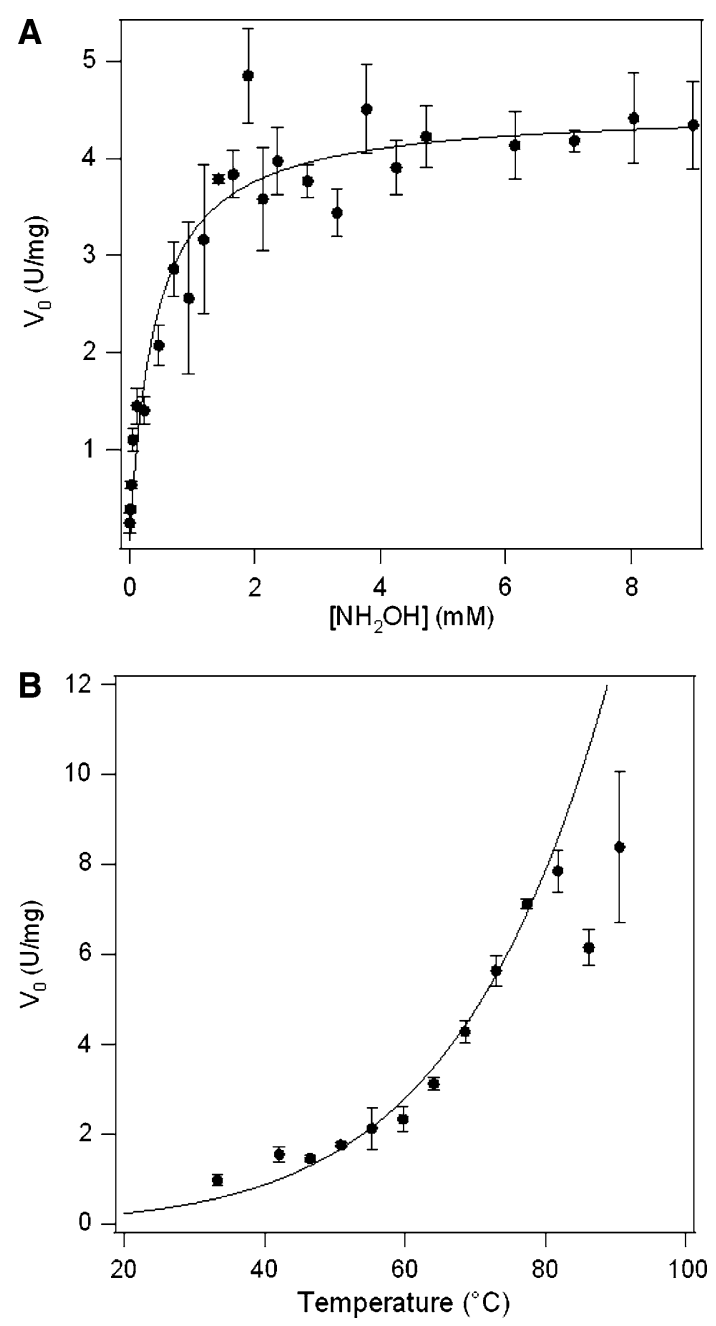

Fig. 1 Kinetic properties of Pyrococcus furiosus hybrid cluster protein (HCP). a Hydroxylamine reduction activity of $P$. furiosus $\mathrm{HCP}$ at $\mathrm{pH} 9.0$ and $70{ }^{\circ} \mathrm{C}$. The line is a least-squares fit to a Michaelis-Menten curve with $K_{\mathrm{m}}=0.40 \pm 0.08 \mathrm{mM}$ and $V_{\max }=4.5 \pm 0.2 \mathrm{U} / \mathrm{mg}$. b Temperature dependence of hydroxylamine reduction activity of $P$. furiosus HCP. The solid line represents a fit of the data points below $80{ }^{\circ} \mathrm{C}$ to the Eyring equation with $\Delta H^{*}=48 \pm 3 \mathrm{~kJ} / \mathrm{mol}$ and $\Delta S^{*}=-93 \pm 10 \mathrm{~J} / \mathrm{K} \mathrm{mol}$ 
Table 1 Comparison of the kinetic parameters of hydroxylamine and hydrogen peroxide reduction activities of hybrid cluster protein (HCP) from different organisms

\begin{tabular}{|c|c|c|c|c|c|c|}
\hline Organism & Class & Substrate & $k_{\mathrm{cat}}^{\mathrm{a}}\left(\mathrm{s}^{-1}\right)$ & $K_{\mathrm{m}}(\mathrm{mM})$ & $k_{\mathrm{cat}} / K_{\mathrm{m}}\left(\mathrm{M}^{-1} \mathrm{~s}^{-1}\right)$ & Reference \\
\hline \multirow[t]{2}{*}{ Desulfovibrio vulgaris } & \multirow[t]{2}{*}{ I } & $\mathrm{NH}_{2} \mathrm{OH}$ & $3.1^{\mathrm{b}}$ & NR & NR & [3] \\
\hline & & $\mathrm{H}_{2} \mathrm{O}_{2}$ & 0.04 & 0.3 & $0.1 \times 10^{3}$ & [11] \\
\hline Rhodobacter capsulatus & II & $\mathrm{NH}_{2} \mathrm{OH}$ & 1.9 & 1 & $1.9 \times 10^{3}$ & [9] \\
\hline \multirow[t]{2}{*}{ Escherichia coli } & \multirow[t]{2}{*}{ II } & $\mathrm{NH}_{2} \mathrm{OH}$ & 396 & 2.5 & $1.59 \times 10^{5}$ & [8] \\
\hline & & $\mathrm{H}_{2} \mathrm{O}_{2}$ & 0.17 & 0.3 & $0.6 \times 10^{3}$ & {$[11]$} \\
\hline Pyrococcus furiosus & III & $\mathrm{NH}_{2} \mathrm{OH}$ & 3.8 & 0.40 & $9.5 \times 10^{3}$ & This work \\
\hline
\end{tabular}

$N R$ not reported

${ }^{\text {a }}$ The temperatures at which the $D$. vulgaris, $R$. capsulatus, and E. coli HCP activities assays were performed were not reported. The activities of the $P$. furiosus enzyme were measured at $70^{\circ} \mathrm{C}$

b Measured at $\mathrm{pH} 7.0$ but reported to be unchanged at $\mathrm{pH} 8.8$

Native PAGE showed that $P$. furiosus $\mathrm{HCP}$ has a native molecular mass of $102 \mathrm{kDa}$. This is consistent with the predicted molecular mass of $102.6 \mathrm{kDa}$ for the $\mathrm{HCP}$ homodimer. Previously characterized HCPs have been found to be monomeric [1].

Pyrococcus furiosus HCP exhibits hydroxylamine reductase activity

HCP catalyzes the two-electron reduction of hydroxylamine to form ammonia and water [7, 8]. Figure 1a shows the rate of hydroxylamine reduction by the recombinant $\mathrm{HCP}$ from $P$. furiosus versus the concentration of hydroxylamine at $\mathrm{pH} 9.0$ at $70{ }^{\circ} \mathrm{C}$. The enzyme exhibits Michaelis-Menten kinetics with $K_{\mathrm{m}}$ of $0.40 \pm 0.08 \mathrm{mM}$ and $V_{\max }$ of $4.5 \pm 0.2 \mathrm{U} / \mathrm{mg}\left(k_{\mathrm{cat}}=3.8 / \mathrm{s}\right)$. The catalytic efficiency $k_{\text {cat }} / K_{\mathrm{m}}=9.5 \times 10^{3} \mathrm{M}^{-1} \mathrm{~s}^{-1}$ shows that the enzyme turnover rate is far from the diffusion-limited value of $10^{8}-10^{9} \mathrm{M}^{-1} \mathrm{~s}^{-1}$; however, the value is comparable to the values of HCPs from other organisms (Table 1). The low catalytic efficiency of all HCPs for hydroxylamine and for hydrogen peroxide suggests that these reactivities may represent minor activities, leaving the major physiological substrate unknown.

Pyrococcus furiosus is a hyperthermophilic organism so it can be expected that its HCP is relatively thermostable. Figure $1 \mathrm{~b}$ shows that $P$. furiosus $\mathrm{HCP}$ indeed exhibits thermostable hydroxylamine reduction activity. The formation of the product, ammonia, was confirmed enzymatically using glutamate dehydrogenase. With RT-PCR, we were able to qualitatively confirm the transcription of $\mathrm{HCP}$ in $P$. furiosus grown on casein and inorganic sulfur (not shown). Additional control PCRs with total RNA as a template showed no bands, confirming that the RNA preparation was not contaminated with (genomic) DNA. These results confirm previous
DNA microarray analysis showing that the $h c p$ gene is transcribed in vivo [13].

EPR spectroscopic characterization of the iron-sulfur clusters of $P$. furiosus HCP

Figure 2 shows EPR spectra of $P$. furiosus $\mathrm{HCP}$ as isolated. In the $g=2$ region the spectrum shows (Fig. 2a) an EPR signal which can be simulated as an $S=1 / 2$ species with $g$ values of $2.010,1.967$, and 1.939. Power saturation of this species at $22.5 \mathrm{~K}$ is characterized by $P_{1 / 2}=43 \mathrm{~mW}$. This $S=1 / 2$ species is assigned to the hybrid cluster; highly similar signals have been found in $E$. coli $\mathrm{HCP}(2.01,1.96$, 1.94) [1] and recombinant D. vulgaris HCP [22].

The low-field signals in Fig. $2 \mathrm{~b}$ probably originate from an excited doublet from the $S=9 / 2$ spin multiplet of a high-spin hybrid cluster as in E. coli HCP [5, 21]. These signals could not be simulated with $S<9 / 2$.

Figure 3 shows the EPR spectra of dithionite-reduced HCP. Upon reduction of the sample with excess sodium dithionite, the resonances that were described above disappear. The spectra are now dominated by a complex signal centered around $g=2.0$ composed of signals with different temperature-dependent relaxation behavior. The signal measured at $22 \mathrm{~K}$ with $g$ values of $2.013,1.89$, and 1.82 (Fig. 3, spectrum A) is attributed to the hybrid cluster. At low temperature a very broad signal is found (Fig. 3, spectrum B) which is similar to that in the EPR of reduced D. vulgaris and D. desulfuricans $\mathrm{HCP}[23,24]$. This signal has been attributed to a spin-admixed $S=3 / 2$ ground state of the $[4 \mathrm{Fe}-4 \mathrm{~S}]^{+}$cluster. This is in accordance with the fact that the $P$. furiosus protein has the same $\mathrm{N}$-terminal [4Fe-4S] cluster binding motif as HCP from $D$. vulgaris and $D$. desulfuricans. The loss of the three-helix bundle of domain 1 in P. furiosus HCP does not appear to alter the environment of the cubane cluster. 

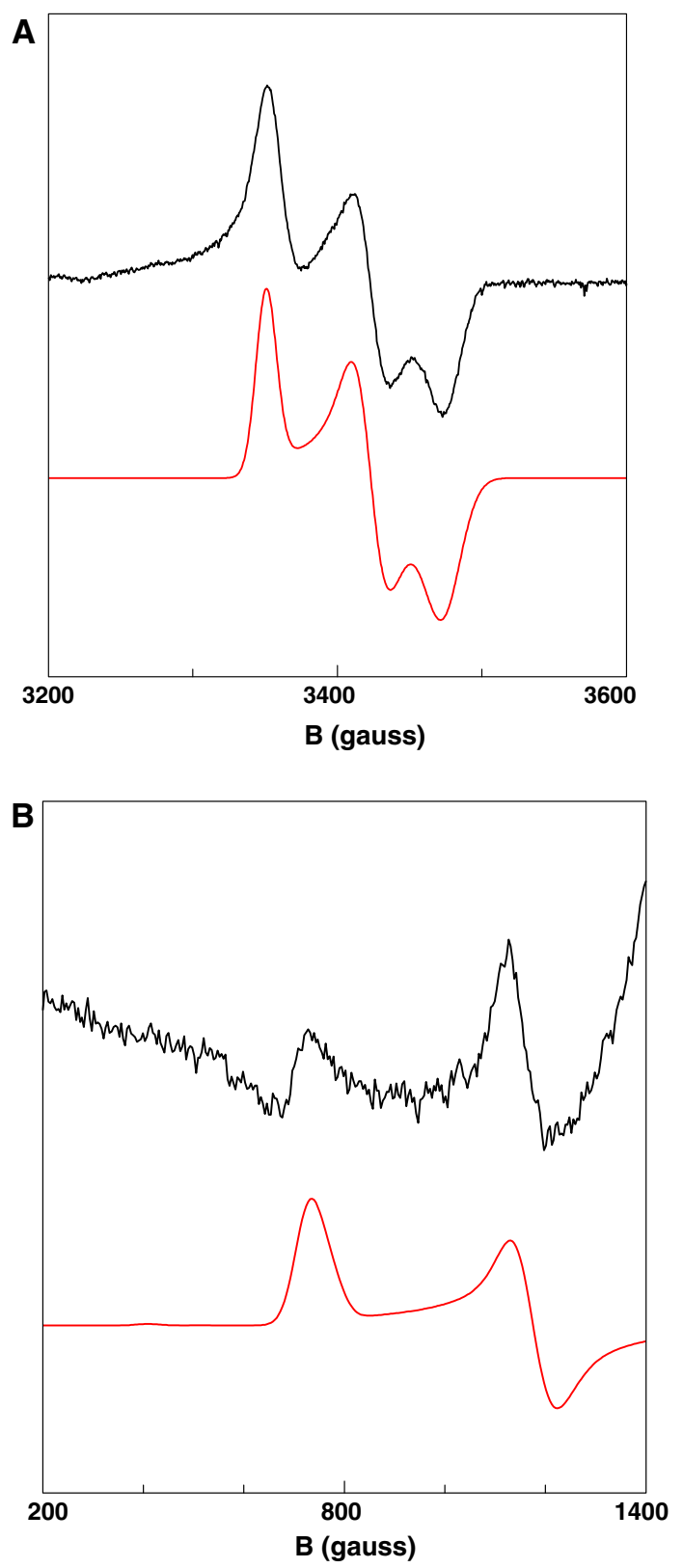

Fig. 2 EPR spectra of as-isolated HCP. a Putative $S=1 / 2$ hybrid cluster signal. The EPR conditions were as follows: microwave frequency $9.427 \mathrm{GHz}$, microwave power $20 \mathrm{~mW}$, modulation frequency $100 \mathrm{kHz}$, modulation amplitude 12.5 gauss, temperature $22.5 \mathrm{~K}$. The simulation parameters were as follows: $g_{x}=1.939$, $g_{y}=1.967, g_{z}=2.010, W_{x}=0.005, W_{y}=0.007, W_{z}=0.008$ (in $g$-value units). b Low-field EPR spectrum of $P$. furiosus HCP as isolated. The EPR conditions were as follows: microwave frequency $9.433 \mathrm{GHz}$, microwave power $20 \mathrm{~mW}$, modulation frequency $100 \mathrm{kHz}$, modulation amplitude 12.5 gauss, temperature $11.8 \mathrm{~K}$. The simulation parameters were as follows: $S=9 / 2, E / D=0.155$, $W_{\text {iso }}=20$ gauss, $\sigma(E / D)=1.5 \%$

\section{HCP family structural comparison}

The crystal structures of $D$. vulgaris $\mathrm{HCP}$ and $D$. desulfuricans $\mathrm{HCP}$ show that the enzyme is composed of three

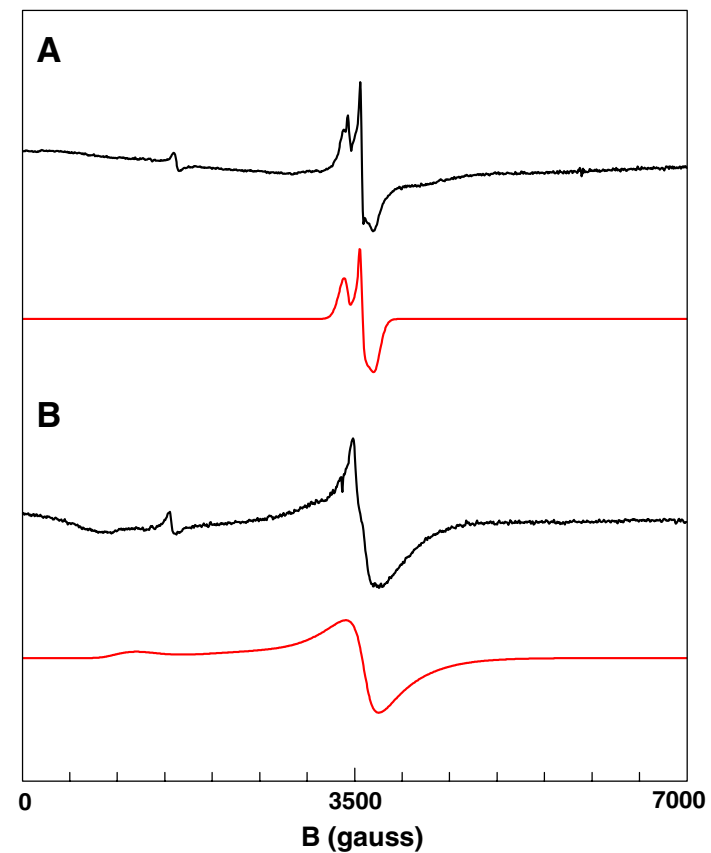

Fig. 3 EPR spectra of HCP reduced with $10 \mathrm{mM}$ sodium dithionite. $A$ EPR spectrum at $12 \mathrm{~K}$. The EPR conditions were as follows: microwave frequency $9.429 \mathrm{GHz}$, microwave power $20 \mathrm{~mW}$, modulation frequency $100 \mathrm{kHz}$, modulation amplitude 12.5 gauss. The simulation parameters were as follows: $g_{x}=1.820, g_{y}=1.890$, $g_{z}=2.013, \quad W_{x}=0.03, \quad W_{y}=0.018, \quad W_{z}=0.035, \quad W_{x y}=0$, $W_{x z}=0.02, W_{y z}=0.025 . B$ EPR spectrum at $7.7 \mathrm{~K}$. The EPR conditions were as follows: microwave frequency $9.432 \mathrm{GHz}$, microwave power $200 \mathrm{~mW}$, modulation frequency $100 \mathrm{kHz}$, modulation amplitude 12.5 gauss. The simulation parameters were as follows: $g_{x}=1.63, g_{y}=1.88, g_{z}=4.8, W_{x}=0.17, W_{y}=0.09$, $W_{z}=1.2, W_{x y}=0.1, W_{x z}=0, W_{y z}=0.1, W$ residual $=0.02$ (all in $g$-value units)

domains [4, 24]. Domain 1 contains the cysteine motif for the cubane cluster and two three-helix bundles that exhibit structural similarity with the molecular chaperone DnaK and the proteasome activator REG $\alpha$ [4]. Domain 2 and domain 3 contain a core of a six-strand parallel twisted sheet and together provide all the ligands to the hybrid cluster. Sequence alignment of $P$. furiosus $\mathrm{HCP}$ with the $D$. vulgaris and $D$. desulfuricans HCPs shows that the deletion in the archaeal HCP sequences results in the loss of one of the two three-helix bundles of domain 1, while the metal binding part is conserved. By overlaying a homology model of $P$. furiosus $\mathrm{HCP}$ with the $D$. vulgaris $\mathrm{HCP}$ structure, one can clearly see the effect of the deletion on the whole structure (Fig. 4). The loss of one of the two three-helix bundles of domain 1 would increase the solvent accessibility of both the cubane and the hybrid cluster if P. furiosus HCP were monomeric like the other HCPs. The dimeric state may be necessary to protect the active site and maintain substrate selectivity.

Interestingly, the three-helix bundle of $\mathrm{HCP}$ domain 1 is also absent in $\mathrm{CO}$ dehydrogenase. $\mathrm{CO}$ dehydrogenase can 

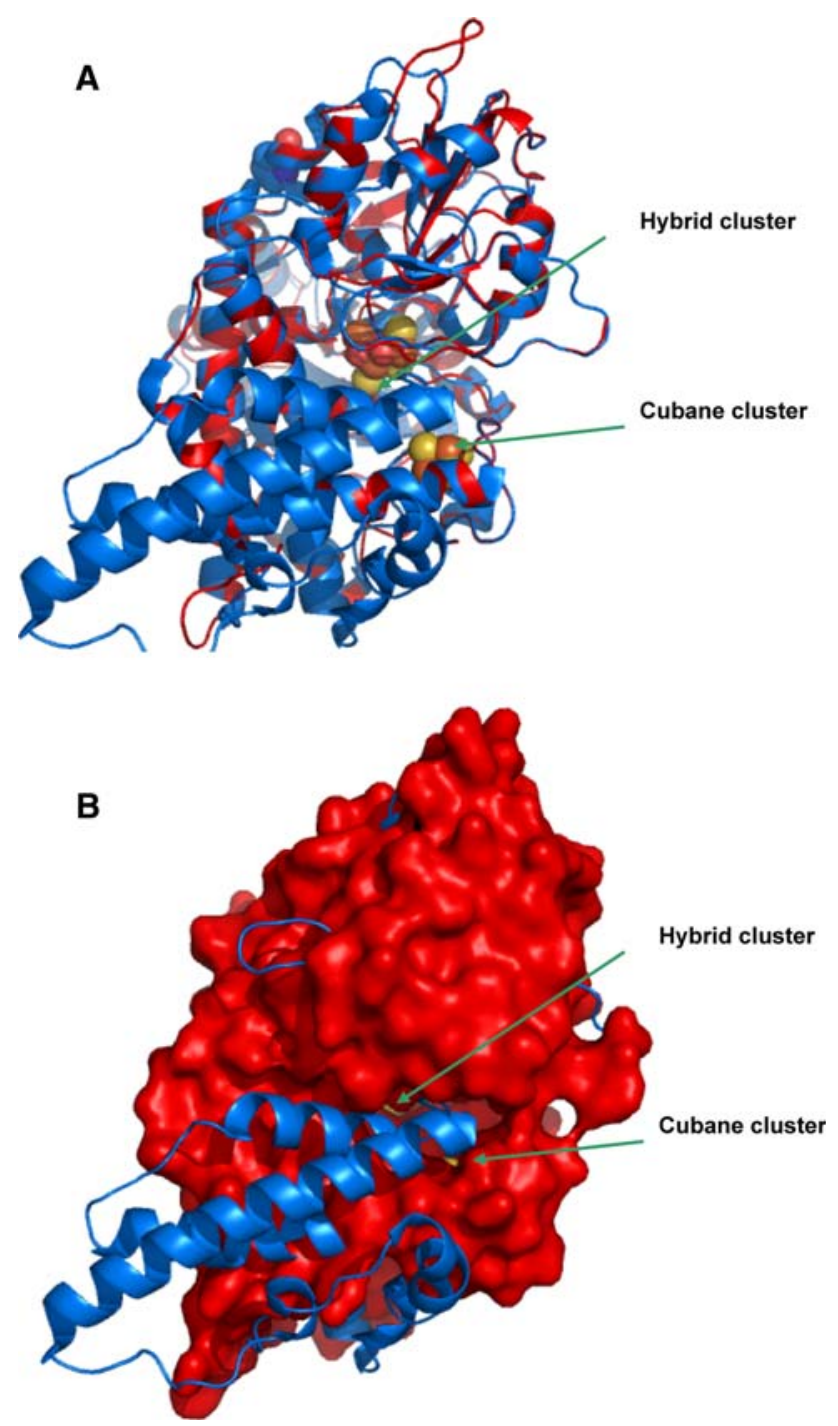

Fig. 4 Structural comparison of P. furiosus HCP and Desulfovibrio vulgaris $\mathrm{HCP}$. a Overlay of the homology model of $P$. furiosus $\mathrm{HCP}$ (red) and the crystal structure of D. vulgaris HCP (Protein Data Bank entry 1GNT) (blue). The effect of the deletion is clearly visible in this picture. One three-helix bundle of domain 1 is lost in the $P$. furiosus HCP, leaving the cubane cluster more exposed to the solvent. b The effect of the deletion on the solvent accessibility of the hybrid cluster and the cubane cluster

occur as a monomer, a homodimer, or an $\alpha_{2} \beta_{2}$ heterotetrametic bifunctional ( $\mathrm{CO}$ dehydrogenase/acetyl-CoA synthase) enzyme. CO dehydrogenase has an extra 45 amino acid sequence preceding the cubane binding motif which is absent in all HCPs. The similarity between $\mathrm{CO}$ dehydrogenases and the class-III HCPs, in particular, has prompted researchers to predict that the class-III HCPs are dimeric unlike the other HCPs [25]. A structural topology was proposed in which the missing helix bundle is replaced by the helix bundle from the other monomer. Here we provide evidence that, at least for one of the class-III HCPs, this is true. The nature of the dimerization interface has to be determined from X-ray crystallographic data.

\section{Discussion}

A class-III HCP from $P$. furiosus was expressed and characterized for the first time. The optimum activity is at approximately $80{ }^{\circ} \mathrm{C}$, confirming the thermostable nature of the protein.

EPR spectroscopy of the recombinant $P$. furiosus $\mathrm{HCP}$ gave signals that can be attributed to a $[4 \mathrm{Fe}-4 \mathrm{~S}]$ cluster and the hybrid cluster. The dithionite-reduced sample showed a $[4 \mathrm{Fe}-4 \mathrm{~S}]^{+}$cluster with a spin-admixed $S=3 / 2$ ground state as in D. vulgaris HCP and D. desulfuricans HCP. Extensive EPR and Mössbauer spectroscopic studies on other HCPs have shown that the hybrid cluster can exist in four different redox states that can be designated as $3+$, $4+, 5+$, and $6+$ according to prismane protein nomenclature [2], where the $6+$ state represents the all-ferric state of the cluster. The $6+$ state is $S=0$, the $5+$ state is a mixture of $S=1 / 2$ and $9 / 2$, the $4+$ state is a mixture of $S=0$ and 4 , and finally the $3+$ state is $S=1 / 2$. In short, the EPR signals from the hybrid cluster are $S=1 / 2$, for the reduced cluster $(3+$ state) and $S=1 / 2$ and $9 / 2$ for the oxidized cluster $(5+$ state). We were able to observe signals for the $5+$ state in as-isolated $P$. furiosus $\mathrm{HCP}$ and for the $3+$ state in dithionite-reduced $P$. furiosus HCP.

Pyrococcus furiosus has a second smaller hcp gene in its genome. This gene encodes a 13.5-kDa protein (Pf6089) that contains four cysteines, but misses several essential residues for the coordination of the cubane and the hybrid cluster. The sequence of residues 1-85 from this "mini-HCP" is nearly identical ( $89 \%$ identity) to that of residues $111-168$ and 200-226 of the full-length HCP. The C-terminal sequence, residues 86-123, does not resemble any known gene product, but provides two of the four cysteines. This "miniHCP" gene is only present in P. furiosus and was not found in any other genome database.

In the light of the enigmatic physiological role of HCP, it is interesting that a close relative of $P$. furiosus, $P$. horikoshii, does not contain the hcp gene in its genome. The genomes of $P$. furiosus and $P$. horikoshii have been compared and analyzed in detail [26]: despite the high sequence identity at the $16 \mathrm{~S}$ ribosmal RNA level, the two genomes have diverged significantly. P. horokoshii has lost a significant number of operons, including several involved in amino acid biosynthesis, polysaccharide degradation, and the tricarboxylic acid cycle. The physiological role of HCP in P. furiosus may be linked to one of these operons.

In conclusion, the deletion of one three-helix bundle of domain 1 , which is common to all class-III HCPs, does not 
diminish hydroxylamine reduction activity. The activity combined with the EPR spectroscopic data indicate that both a regular $[4 \mathrm{Fe}-4 \mathrm{~S}]$ cubane cluster and a hybrid cluster are present in P. furiosus HCP. Hydroxylamine reduction activity has now been measured for HCPs of all three classes and hydrogen peroxide reduction has been measured for HCPs from classes I and II; however, the low catalytic efficiencies for all these reactions indicate that these are minor promiscuous activities. The physiological substrate of HCP is still to be discovered.

Deletion of a 116 amino acid stretch from domain 1 may offer a site at which dimerization occurs. The deletion also appears to lead to a more compact structure of the monomer, which together with the dimeric structure could be a mechanism to increase the thermal stability of this class-III archaeal HCP.

Acknowledgment This work was supported by the Netherlands Research School Combination-Catalysis (NRSC-C).

Open Access This article is distributed under the terms of the Creative Commons Attribution Noncommercial License which permits any noncommercial use, distribution, and reproduction in any medium, provided the original author(s) and source are credited.

\section{References}

1. Pierik AJ, Wolbert RB, Mutsaers PH, Hagen WR, Veeger C (1992) Eur J Biochem 206:697-704

2. Arendsen AF, Hadden J, Card G, McAlpine AS, Bailey S, Zaitsev V, Duke EHM, Lindley P, Krockel M, Trautwein AX, Feiters MC, Charnock JM, Garner CD, Marritt SJ, Thomson AJ, Kooter IM, Johnson MK, van den Berg WAM, van Dongen WMAM, Hagen WR (1998) J Biol Inorg Chem 3:81-95

3. Aragão D, Macedo S, Mitchell EP, Romao CV, Liu MY, Frazão C, Saraiva LM, Xavier AV, LeGall J, van Dongen WMAM, Hagen WR, Teixeira M, Carrondo MA, Lindley P (2003) J Biol Inorg Chem 8:540-548

4. Cooper SJ, Garner CD, Hagen WR, Lindley PF, Bailey S (2000) Biochemistry 39:15044-15054

5. van den Berg WAM, Hagen WR, van Dongen WMAM (2000) Eur J Biochem 267:666-676
6. Hagen WR, van den Berg WA, van Dongen WMAM, Reijerse EJ, van Kan PJM (1998) J Chem Soc Faraday Trans 94:29692973

7. Heo J, Wolfe MT, Staples CR, Ludden PW (2002) J Bacteriol 184:5894-5897

8. Wolfe MT, Heo J, Garavelli JS, Ludden PW (2002) J Bacteriol 184:5898-5902

9. Cabello P, Pino C, Olmo-Mira F, Castillo F, Roldán MD, Moreno-Vivián C (2004) J Biol Chem 279:45485-45494

10. Filenko N, Spiro S, Browning DF, Squire D, Overton TW, Cole J, Constantinidou C (2007) J Bacteriol 189:4410-4417

11. Almeida CC, Romao CV, Lindley P, Teixeira M, Saraiva LM (2006) J Biol Chem 281:32445-32450

12. Kim CC, Monack D, Falkow S (2003) Infect Immun 71:31963205

13. Schut GJ, Brehm SD, Datta S, Adams MWW (2003) J Bacteriol 185:3935-3947

14. Arendsen AF, Veenhuizen PTM, Hagen WR (1995) FEBS Lett 368:117-121

15. Adams MWW, Holden JF, Menon AL, Schut GJ, Grunden AM, Hou C, Hutchins AM, Jenney FEJ, Kim C, Ma K, Pan G, Roy R, Sapra R, Story SV, Verhagen MFJM (2001) J Bacteriol 183:716724

16. Hennessy DJ, Reid GR, Smith FE, Thompson SL (1984) Can J Chem 62:721-724

17. Lundin A, Aasa R (1972) J Magn Reson 8:70-73

18. Hagen WR, Hearsen DO, Harding LJ, Dunham WR (1985) J Magn Reson 61:233-244

19. Hagen WR (2007) Mol Phys 105:2031-2039

20. Bates PA, Kelley LA, MacCallum RM, Sternberg MJ (2001) Protein Struct Funct Genet (Suppl 5):39-46

21. Pereira AS, Tavares P, Krebs C, Huynh BH, Rusnak F, Moura I, Moura JJG (1999) Biochem Biophys Res Commun 260:209-215

22. van den Berg WAM, Stevens AAM, Verhagen MFJM, van Dongen WMAM, Hagen WR (1994) Biochim Biophys Acta 1206:240-246

23. Moura I, Tavares P, Moura JJG, Ravi N, Huynh BH, Liu MY, LeGall J (1992) J Biol Chem 267:4489-4496

24. Macedo S, Mitchell EP, Romao CV, Cooper SJ, Coelho R, Liu MY, Xavier AV, LeGall J, Bailey S, Garner CD, Hagen WR, Teixeira M, Carrondo MA, Lindley P (2002) J Biol Inorg Chem 4-5:514-525

25. Aragão D, Mitchell EP, Frazão C, Carrondo MA, Lindley $P$ (2008) Acta Crystallogr D 64:665-674

26. Meader DL, Weiss RB, Dunn DM, Cherry JL, Conzalez JM, DiRuggiero J, Robb FT (1999) Genetics 152:1299-1305 